ARTIGOS

\title{
A IMPORTÂNCIA DO PLANO DE NEGÓCIO PARA O SUCESSO E A LONGEVIDADE DAS ORGANIZAÇÕES
}

\section{RESUMO}

Este artigo viabilizou um estudo dos índices do empreendedorismo nos últimos dez anos, por meio de dados disponibilizados pelo SEBRAE, pelo IBGE e afins. O estudo teve como objetivo analisar a importância do plano de negócio para a longevidade das organizações. Foram analisados dados que relacionam os tipos de varejo, de gênero, de idade dos empreendedores e a proporção de empreendedores que buscam algum tipo de conhecimento e apoio para iniciar seu empreendimento. A pesquisa se caracteriza como um estudo bibliográfico e documental, para tal recorte, foram utilizados relatórios disponibilizados dos últimos dez anos dos órgãos supracitados, entre outros autores utilizados que sofreram revisão bibliográfica prévia. Alcançaram-se informações que possibilitaram entender melhor os tipos de empreendedores e como eles se comportam na economia. Concluiu-se que empreendedores que buscam conhecimento e que executam o plano de negócios tendem a ter sucesso no mercado, acompanhados pelo grande crescimento do gênero feminino nos índices do empreendedorismo.

Palavras-chave: Empreendedorismo. Plano de Negócios. SEBRAE.

\section{INTRODUÇÃO}

O Plano de Negócio trata-se de uma ferramenta importante para as organizações, é um projeto que trata de todos os aspectos

Paula Cristina de Moura Fernandes paulacristinam.fernandes@gmail.com Mestranda pela Universidade Federal de Minas Gerais (UFMG). Professora Subst. na Universidade Federal de Viçosa (UFV).

\footnotetext{
Guilherme Marques Porto guilherme.m.p@hotmail.com Graduando em Administração pela Universidade Federal de Viçosa (UFV).
} da empresa, como financeiro, econômico, operacional, marketing, análise de mercado, mapeamento para decisões, entre outros. No entanto, para alguns empreendedores nascentes, essa não é uma ferramenta de fácil acesso ou relevante, e isso se torna um fator que influencia no sucesso dessas organizações.

Por se tratar de um fenômeno rotineiro, em todo o país, empreendedores abrem e fecham os seus negócios diariamente, pois é um mercado muito volátil. Esses empreendedores estão, constantemente, sendo observados por órgãos de apoio que criam ferramentas para auxiliá-los em todo o território nacional. Acredita-se, então, que existe um problema na postura dos profissionais 
entrantes no mercado com seu próprio negócio em relação ao plano de negócio.

Para compreender a importância dos planos de negócios, foram utilizados vários autores, como Dolabela (2006), Baron e Shane (2013), Hisirich, Peters e Shepherd (2009), entre outros, e, como principal marco teórico, o autor Dornelas (2014), que tem a seguinte definição sobre o plano de negócio: faz com que seja possível entender e delinear diretrizes para seu empreendimento, acertar mais as decisões, gerenciando de uma maneira eficaz, controlar a empresa, tomar as decisões necessárias, captar recursos junto a bancos ou investidores, encontrar, nas oportunidades, maneiras de deixar a empresa mais competitiva e estabelecer uma comunicação entre todos os elos internos e externos.

De acordo com Instituto Brasileiro de Geografia e Estatística (BÔAS, 2015), metade das empresas fecham suas portas após quatro anos. Esse fato torna este trabalho relevante socialmente, justificando o presente assunto que tem o objetivo de conscientizar os empreendedores da importância da utilização dessas ferramentas e a pretensão de alcançar todos para uma conscientização, para que seja promovida a procura por essas ferramentas e esses órgãos de apoio e, consequentemente, o maior o sucesso das empresas.

O trabalho tem como objetivo principal analisar o impacto dos planos de negócio e dos planejamentos no sucesso e na longevidade das organizações. Para tanto, este artigo tem como objetivos específicos analisar os gêneros dos empreendedores, a taxa de entrantes e dos já estabelecidos no mercado, o nível de instrução, a evolução do empreendedorismo dos últimos dez anos, a evolução do empreendedorismo estabelecido e de entrante no mercado por gênero do mesmo período e, por fim, a porcentagem desses profissionais que procuraram algum órgão de apoio para instruí-los no planejamento do seu negócio nos últimos dez anos.

Para a construção do referencial teórico, discorreu-se sobre as teorias que abordam as principais características de um empreendedor, qual é a importância dele para economia do país e a relevância do plano de negócios para as organizações. As análises foram realizadas a partir dos relatórios disponibilizados pelo SEBRAE, IBGE dos últimos dez anos, contendo informações relevantes para a formação de um empreendedor de sucesso.

Em seguida, foram construídos os métodos investigativos do estudo, que caracterizam a pesquisa como descritiva, tendo como objetivo descrever os dados disponibilizados pelo SEBRAE e as opiniões dos autores sobre o assunto, tanto sobre o plano de negócio quanto sobre os impactos econômicos que podem causar às organizações. Os dados foram analisados qualitativamente com a produção de gráficos em que os índices foram expostos e discutidos em relação as suas respectivas importâncias. E, por fim, dada uma sugestão sobre possíveis estudos futuros e dicas para os empreendedores obterem maior sucesso e longevidade em seus respectivos empreendimentos.

\section{O EMPREENDEDORISMO}

O empreendedorismo surgiu em territórios nacionais quando algumas entidades foram formadas, como o SEBRAE, o que ocorreu na década de noventa. A primeira utilização desse termo foi na Idade Média. "Esse indivíduo não assumia grandes riscos, e apenas gerenciava os projetos, utilizando os recursos disponíveis, geralmente provenientes do governo do país." (DORNELAS, 2014, p. 19).

No século XVII, observa-se o primeiro indício de que o empreendedor deveria correr alguns riscos. A partir desse momento, seriam feitos contratos com o governo e o lucro ou o prejuízo no final do serviço prestado seria do empreendedor.

No século seguinte, houve a total separação do capitalista e do empreendedor. No final do século XIX e no início do século XX, começaram a confundir empreendedores com gerentes e administradores, devido a uma análise que é feita apenas nas funções rotineiras de cada um, o que acontece até os dias atuais. Tal fato deu origem a um velho jargão: "todo empreendedor necessariamente deve ser um bom administrador para obter o sucesso, no entanto, 
nem todo bom administrador é um empreendedor." (DORNELAS, 2014, p. 20).

Então, os empreendedores são profissionais visionários que têm uma boa visão de futuro, acreditando sempre em seus sonhos. Esses profissionais são conhecidos por tomarem decisões rapidamente, tomando decisões boas em momentos cruciais. Eles fazem a diferença, pois valorizam o produto que lançam no mercado, exploram oportunidades e são capazes de criar equilíbrio em um ambiente turbulento, aproveitando sempre as oportunidades. São determinados e dinâmicos, com seu total comprometimento, atravessam os obstáculos com mais facilidade, dedicando todo o seu tempo ao negócio; são comumente otimistas e apaixonados, o dinheiro não é o mais importante, mas a satisfação de um trabalho bem feito (MAMEDE; MOREIRA, 2005).

São profissionais independentes e donos do próprio destino, ficam ricos mesmo que esse não seja o objetivo principal. Os empreendedores são ótimos líderes e valorizam os funcionários, obtendo o respeito deles. Constroem uma boa rede de relacionamentos, planejam todas suas ações, até mesmo, antes de começar o empreendimento e estão sempre aprofundando seus conhecimentos. Assumem riscos, mas sempre calculados, e criam valores para a sociedade a partir da movimentação que eles fazem na economia.

Ao encontro das definições de Dornelas, os autores Scholz e Caussi $(2017$, p. 3) explanam que "a soma destas características tornam estes indivíduos imprescindíveis para a criação de novos negócios, é através deles que surgem novas ideias e concepções de mercado."

O plano de negócios é fundamental para a criação de qualquer empresa, mas ainda não é obrigatório, o que influencia no índice de mortalidade das organizações, tornando um número relevante para as médias e as pequenas empresas. Segundo Baron e Shane (2013, p. 185), fazer um plano de negócio é uma atividade muita cansativa e trabalhosa, já que "são necessárias muitas horas de pensamento cuidadoso, seguidas por números igual ou maior de horas para conversão desses pensamentos em um documento escrito."

A partir, então, do plano de negócio, é possível realizar tarefas que, sem aquela ferramenta, dificilmente se teria êxito, por exemplo, captar recurso. Dolabela (2006, p. 87) afirma categoricamente que "o dinheiro é para o empreendedor o que o pincel e a tinta são para o pintor: ferramentas inertes que, nas mãos certas, podem criar maravilhas."

Essa ferramenta, principalmente nos estágios iniciais, não se torna obsoleta com o passar dos anos, pois tem-se como uma das principais etapas do plano de negócio conseguir gerenciar a empresa criada, ou seja, seguir à risca as metas e a execução do que foi planejado anteriormente. "O plano estará finalizado quando o empreendedor conhecer melhor o mercado, os produtos ou serviços a serem comercializadas, a equipe administrativa e as necessidades financeiras do empreendimento." (HISIRICH; PETERS; SHEPHERD, 2009, p. 218).

A ferramenta deve ser desenvolvida de forma persuasiva; o empreendedor deve encarar a confecção desse documento como uma situação competitiva, então o documento deve prender a atenção do leitor rapidamente, caso não, esse profissional pode considerar que será perda de tempo e de dinheiro. "O essencial é a qualidade da ideia por trás do novo empreendimento e a competência da pessoa ou das pessoas que a formularam. Se a ideia não for sensata e tiver pouco potencial econômico, os investidores experientes reconhecerão." (BARON; SHANE, 2013, p. 189). No entanto, não há um modelo padrão para se seguir, cada empreendedor deve escolher o que atende as suas necessidades (DORNELAS, 2014).

Destarte, faz que o plano de negócio seja utilizado como ferramenta estratégica, pois não possui um modelo único, como receita de sucesso, então cada profissional desenvolve sua melhor habilidade, transformando seus pontos fortes em vantagens competitivas no mercado. Sendo assim, o uso da ferramenta se torna importante para as organizações e para a economia mundial, como poderá ser visto nas discussões dos dados a seguir. 


\section{METODOLOGIA DA PESQUISA}

A pesquisa realizada tem caráter descritivo, com o objetivo de analisar os impactos que a elaboração de um plano de negócios pode causar em uma organização, em sua fundação, em sua duração no mercado, em seus objetivos e, até mesmo, no futuro da empresa. "As pesquisas deste tipo têm como objetivo primordial a descrição das características de determinada população ou fenômeno ou o estabelecimento de relações entre variáveis." (GIL, 2008, p. 28).

O estudo é caracterizado como pesquisa bibliográfica e documental como método para atingir os objetivos do estudo, deixando o tema mais acessível e claro. A pesquisa se caracteriza como bibliográfica e documental devido à exigência de publicação anterior aos estudos, sendo assim todos os arquivos utilizados para obter os dados e fazer a pesquisa secundária já passaram por uma revisão anteriormente. Para tanto, serão analisadas várias bibliografias, e essas informações serão destinadas ao presente artigo. "A documentação é a parte mais importante do trabalho científico, pois consiste no levantamento de material que vai fornecer a solução para o problema estudado." (OLIVEIRA NETTO, 2006, p. 48).

A respeito de pesquisas bibliográficas, depreendem-se os ensinamentos de Gil (2008) e Cervo, Bervian e Silva (2007). A pesquisa bibliográfica e a pesquisa documental são feitas por meio de material já existente, publicados anteriormente, como livros, artigos científicos, teses e dissertações. Foram utilizados, para este estudo, os relatórios dos últimos dez anos disponibilizados pelo GEM (Global Entrepreneurship Monitor). O SEBRAE disponibiliza várias ferramentas para auxiliar os futuros empresários e empreendedores em suas decisões, algumas dessas ferramen- tas são o Sebraetec, o Programa Nacional de Educação Empreendedora, o Negócio a Negócio e o GEM. Essas ferramentas são completas e podem fornecer para esses profissionais todos os tipos de informações que eles possam precisar.

Já nos relatórios GEM, os empreendedores conseguem obter informações de quantas empresas começaram ou terminaram suas atividades em cada ano, subdivididas por setores e áreas de atuação, quantas dessas empresas utilizaram um plano de negócio como ferramenta de planejamento estratégico e quantas empresas utilizaram órgãos de apoio como o SEBRAE, o Serviço Nacional de Aprendizagem Rural (SENAR), o Serviço Nacional de Aprendizagem Comercial (SENAC), entre outros. Ainda há outros empreendedores que resolveram abrir seu próprio negócio sem nenhum planejamento prévio. E, a partir desses dados, as análises serão discutidas e tornam-se relevantes para a sociedade.

\section{ANÁLISES DOS RESULTADOS}

\subsection{DEMOGRÁFICO}

Neste tópico, serão descritas quais as variações que ocorreram nos últimos anos em relação ao gênero, à faixa etária em estágio inicial e em já estabelecidos, além dos níveis de escolaridade encontrados nos empreendedores.

Como se pode observar no Gráfico 1, estão relacionadas às porcentagens de pessoas do sexo masculino e feminino em empreendimentos. Em ambos os tipos de estabelecimento, o percentual de homens é maior, porém, quando se fala em empreendimentos em estágio inicial, as mulheres se encontram mais próximas do que quando se fala em empreendimentos já estabelecidos. Pode-se perceber, então, que tem aumentado o número de mulheres empreendedoras nos últimos anos. 


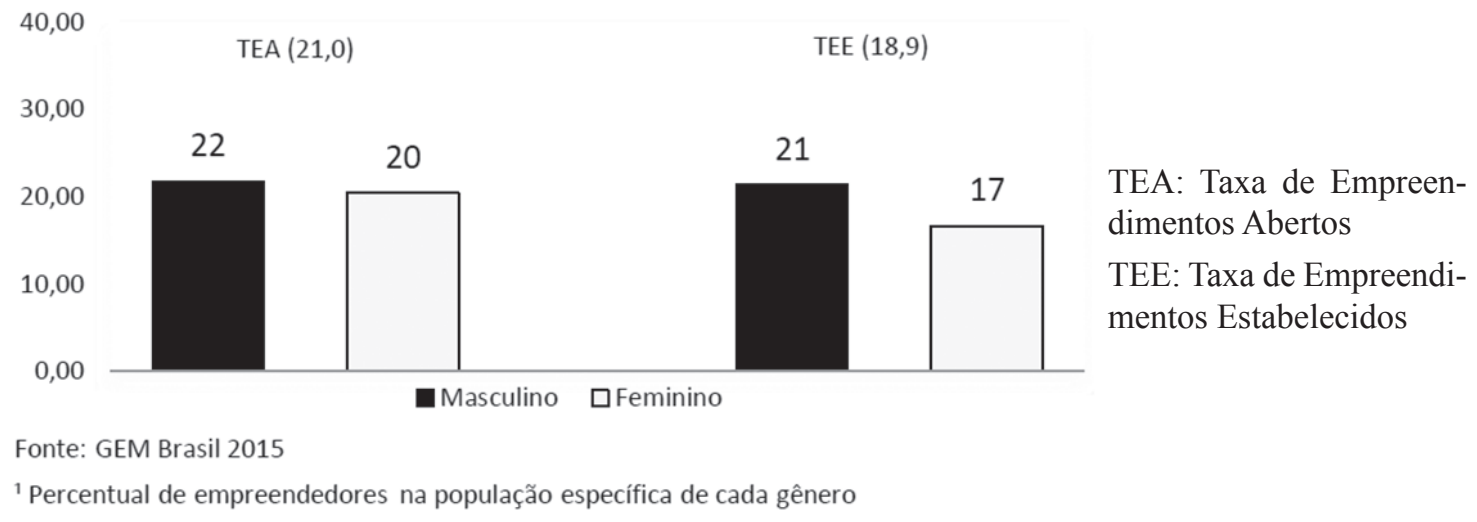

Gráfico 1 - Taxa por gênero de estabelecimentos em estágio inicial e já estabelecidos Fonte: (GEM, 2015, online).

O Gráfico 2 exibe como os estabelecimentos iniciais, caracterizados pela juventude aparente, os números de jovens entre 25 e 34 anos são maiores do que quando é comparados diretamente com as taxas de empreendedores estabelecidos no mercado há mais tempo, nestes predominam-se empreendedores mais velhos na faixa etária de 45 a 54 anos.

No entanto, podem-se considerar dois fatores. Com as crises financeiras iniciadas nos anos de 2008 e 2014, pessoas mais jovens sem alternativa optaram por empreender. O outro ponto que deve ser levado em consideração é que, para a pessoa se tornar estabelecida no mercado, não é rápido e fácil, logo, encontram-se, nessa posição, pessoas mais experientes que já atuam no mercado há mais tempo.

\subsection{EVOLUÇÃO E PLANEJAMENTO DOS EMPREENDEDORES}

Neste tópico, serão analisadas quais as porcentagens de empreendedores novos e nascentes no mercado e, dessa proporção de empreendedores, quais deles optaram por empreender por necessidade ou por oportunidade, quantas empresas fecharam nos últimos dez anos e quais delas procuraram algum órgão de apoio para fazer algum tipo de planejamento estratégico.

Pode-se observar, no Gráfico 3, que houve um grande crescimento nos números de empresas novas e nascentes nos últimos anos. De acordo com o GEM (2015), uma média de 52 milhões de pessoas entre 18 e 64 anos estavam diretamente ou indiretamente envolvidas com

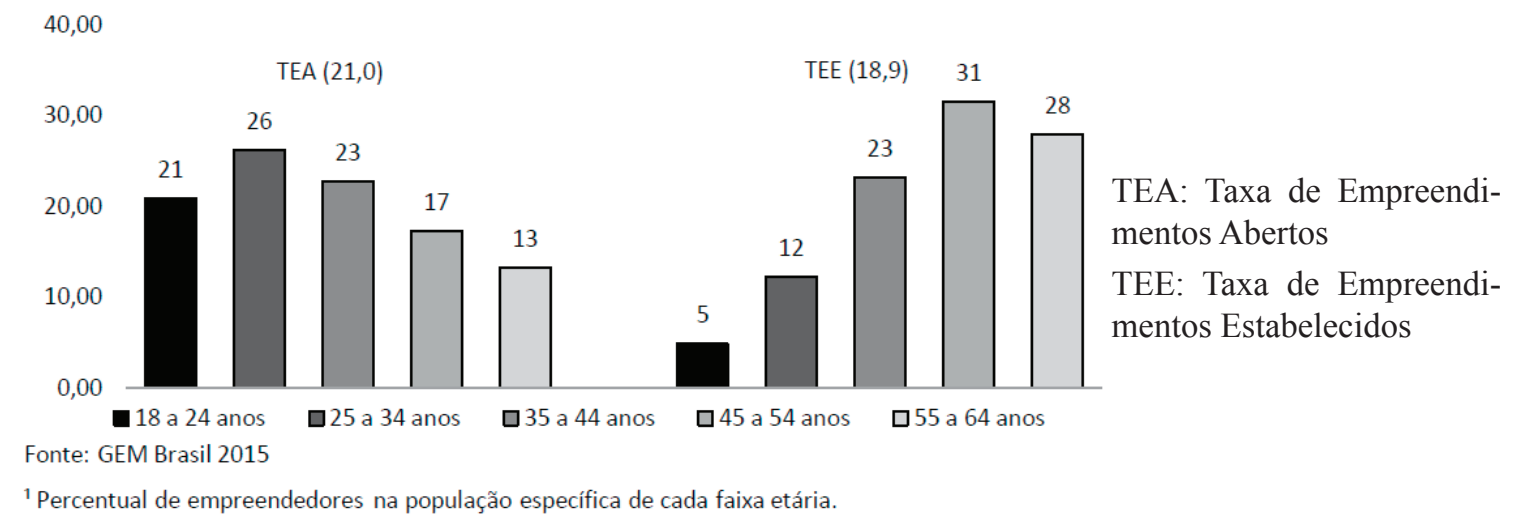

Gráfico 2 - Taxa por idade de estabelecimentos em estágio inicial e já estabelecidos Fonte: (GEM, 2015, online). 
o empreendedorismo, um aumento significati- $\quad$ vo em relação aos últimos anos.

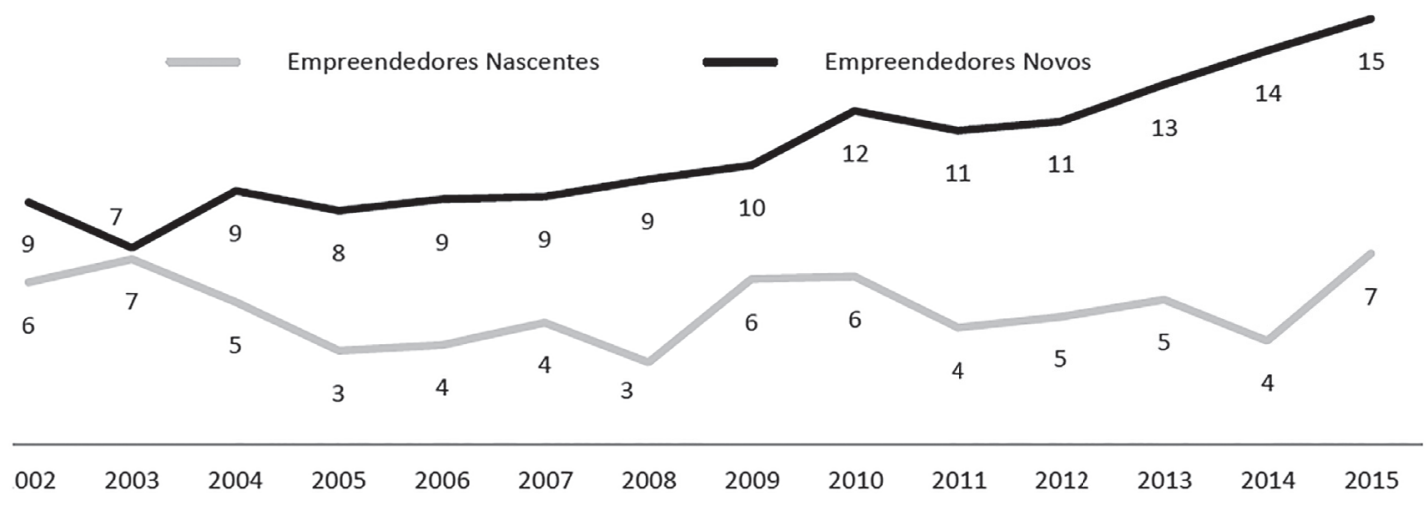

Fonte: GEM Brasil 2015

${ }^{1}$ Percentual da população de 18 a 64 anos.

Gráfico 3 - Empreendedores novos e nascentes

Fonte: (GEM, 2015, online).

Um fator importante de se destacar no Gráfico 4 é a relação de empreendedores por necessidade devido às crises mencionados no item superior. Nestes períodos, os números de empreendedores por necessidade foram maiores do que em outros momentos, o que caracte- riza uma anormalidade na economia. O gráfico demonstra uma alavancagem em 2014 e pode-se associar ao mesmo período do começo do desemprego estrutural em massa, o que, mais tarde, acarreta a mesma proporção no índice de mortalidade das organizações.

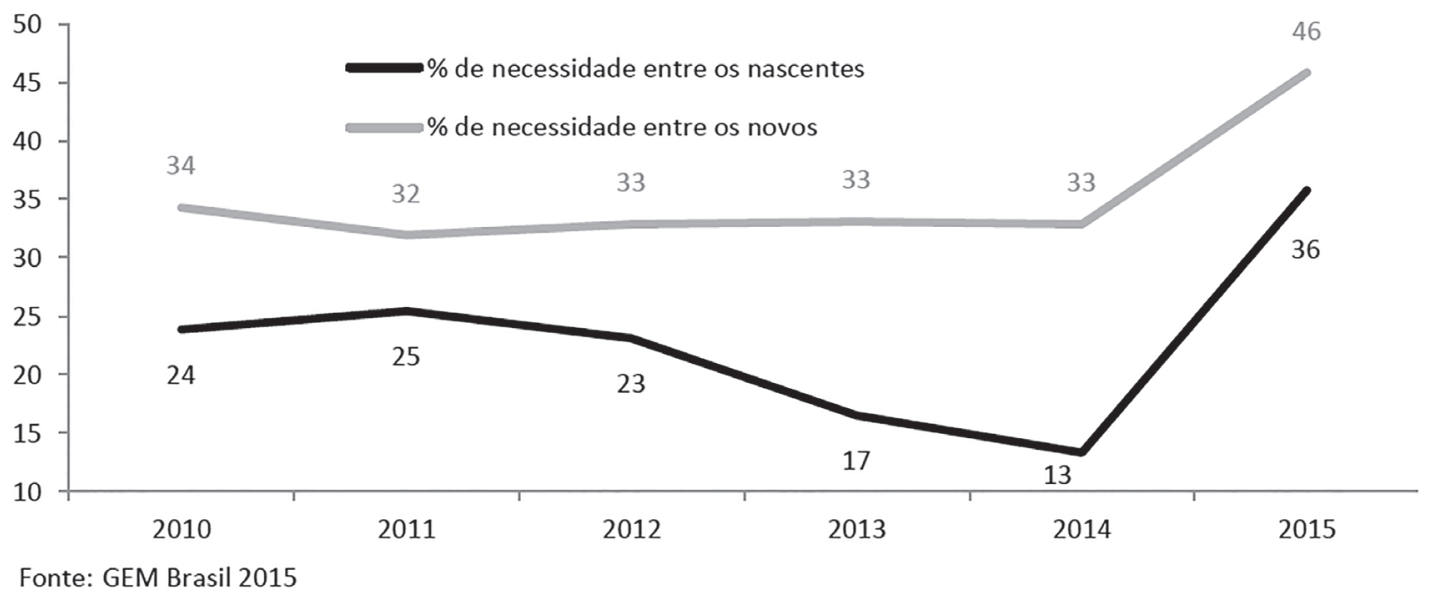

Gráfico 4 - Empreendedores por necessidade em relação a novos e nascentes Fonte: (GEM, 2015, online).

Observando as taxas de evolução do empreendedorismo no país dispostas no Gráfico 5, pode-se perceber que o empreendedorismo é uma tendência no país. Houve uma evolução na taxa de empreendedores entrantes no mercado no ano de 2008 que perdurou até o ano de 2010.
Economistas e especialistas acreditam que essa pequena alavancagem é advinda da crise que o país passou no ano de 2008. Depois de 2010, houve algumas pequenas quedas nessas taxas, ocorrendo outro aumento no ano de 2014 devido à nova crise enfrentada pelo país. 


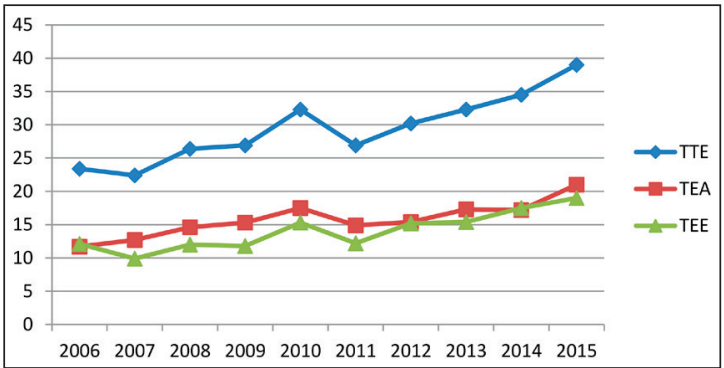

Gráfico 5 - Taxa de evolução do empreendedorismo Fonte: elaborado pelo autor de acordo com dados contidos nos GEM (2012, 2013, 2014, 2015).

TTE - Taxa Total de Empreendimentos TEA - Taxa de Empreendimentos Abertos

TEE - Taxa de Empreendimentos Estabelecidos

Em relação à evolução dos gêneros em empresas entrantes no mercado e nas já estabelecidas observados no Gráfico 6, é relevante destacar o aumento da participação do gênero feminino. Quando se olham empresas já estabelecidas (TEE), as mulheres se encontram abaixo no gráfico, porém, se analisarmos empresas entrantes no mercado (TEA), o gênero feminino se aproxima do gênero masculino, chegando, até mesmo, a ultrapassar, como no ano de 2013, de 2014 e de 2015.

Isso pode acarretar, no futuro, uma maior participação do gênero feminino em negócios já estabelecidos, uma vez que estão maiores os número de empresas nascentes. Com o aporte social que essas pessoas têm dos programas desenvolvidos pelo SEBRAE, pelo SENAR e afins, a tendência é que, efetivamente, ultrapassem esses números e diminuam significativamente os índices de mortalidade.
O Gráfico 7 traz a proporção de empreendedores que procuraram algum tipo de apoio para abrir o próprio negócio. Como se pode observar, aqueles que procuram algum apoio ou incentivo são poucos em relação àqueles que abrem seus negócios sem procurar nenhum órgão especializado. No ano de 2011, 79,2\% desses profissionais resolveram arriscar sem nenhum apoio ou planejamento. $\mathrm{O}$ número em 2012 foi de 84,5, e de 85,2 e 84,1, respectivamente, nos anos de 2013 e 2014.

$\mathrm{O}$ órgão mais procurado por aqueles que acreditam que esse apoio pode ser importante é o SEBRAE, tendo uma procura de $13,0 \%$ em $2012,9,2 \%$ em 2013, 10,4\% em 2014 e, no ano de 2015, 9,3\%. Todos esses dados foram tirados dos Relatórios Executivos. Foram analisados os relatórios desde o ano de 2007, porém os dados se encontram disponíveis a partir do ano de 2011, ano em que o relatório passou a ser estruturado de uma maneira diferente.

De acordo com IBGE (FONSECA, 2011), metade das empresas fecham suas portas após quatro anos. Esse é um número preocupante, pois empreendedores estão investindo seu capital e não estão obtendo o retorno esperado. A revista Gestão e Negócios lançou uma reportagem abordando o assunto. Nessa reportagem, é exposto pelo escritor José Carlos Fonseca (FONSECA, 2011) que os dados publicados pelo IBGE mostram que a cada 100 empresas abertas no Brasil 48 fecham suas portas, destacando as razões que o SEBRAE especifica como as principais causadoras.

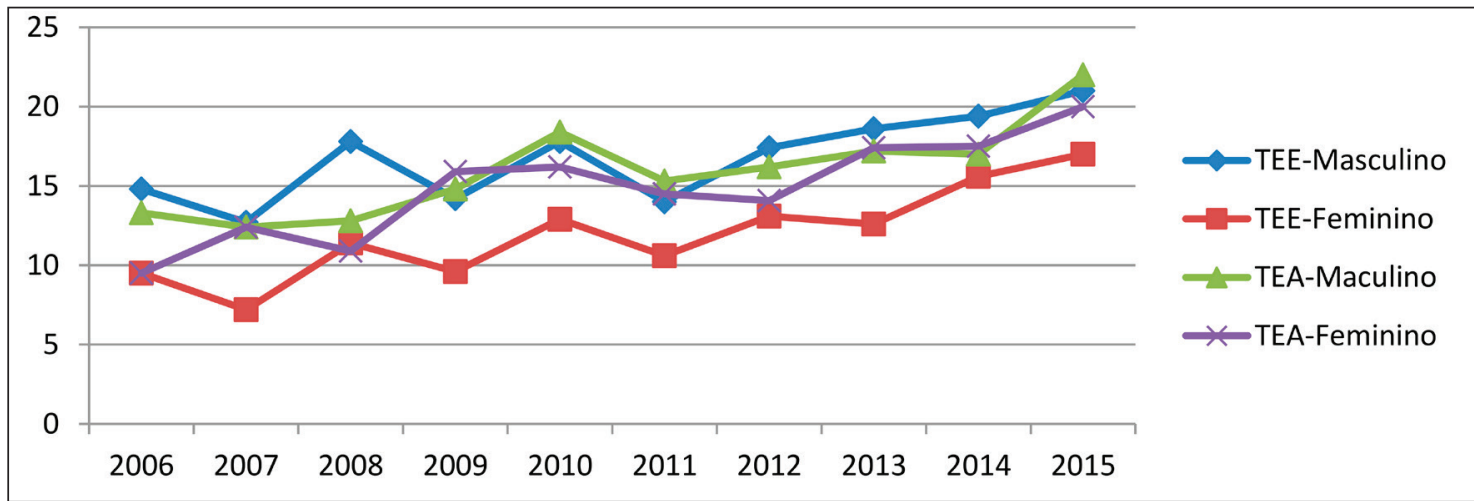

Gráfico 6 - Evolução nas empresas estabelecidas e entrantes no mercado por gênero

Fonte: elaborado pelo autor de acordo com dados contidos nos GEM (2012, 2013, 2014, 2015).

TEA - Taxa de Empreendimentos Abertos TEE - Taxa de Empreendimentos Estabelecidos 
Dentre as razões, estão a falta de planejamento e a cópia de modelos já existente, empresários tentam trabalhar como uma empresa que já está estabilizada no mercado, o que é um grande erro, uma vez que a inovação é fundamental para qualquer negócio. Além disso, não acompanhar o dia a dia da empresa, falta de controle do fluxo de caixa é um fator que pode ser relacionado com a falta de planejamento, falta de divulgação da marca e o último dos problemas destacado é a dificuldade de se adaptar ao mercado, aspecto que, no plano de negócio, também seriam estudadas quais as necessidades do mercado, quais as oportunidades, e, com toda a análise tática e operacional, o empreendedor estaria mais preparado para o mercado. que teriam e os hábitos deles. 39\% não sabiam qual o seu capital de giro mínimo para gerir seu negócio, 38\% não sabiam quem seriam seus concorrentes, $37 \%$ não sabiam a melhor localização para seu negócio, 33\% não sabiam quem seriam seus fornecedores.

Não são todas as empresas que fecham apenas por falta de planejamento, algumas empresas fecham por problemas com sócios, outros profissionais passam por problemas particulares e acabam encerrando suas atividades, entre outros motivos. Mas, de acordo com SEBRAE, de todas as empresas que fecham suas portas nesse período com menos de quatro anos, $60 \%$ é devido à falta de planejamento prévio, de confecção e de execução de um pla-

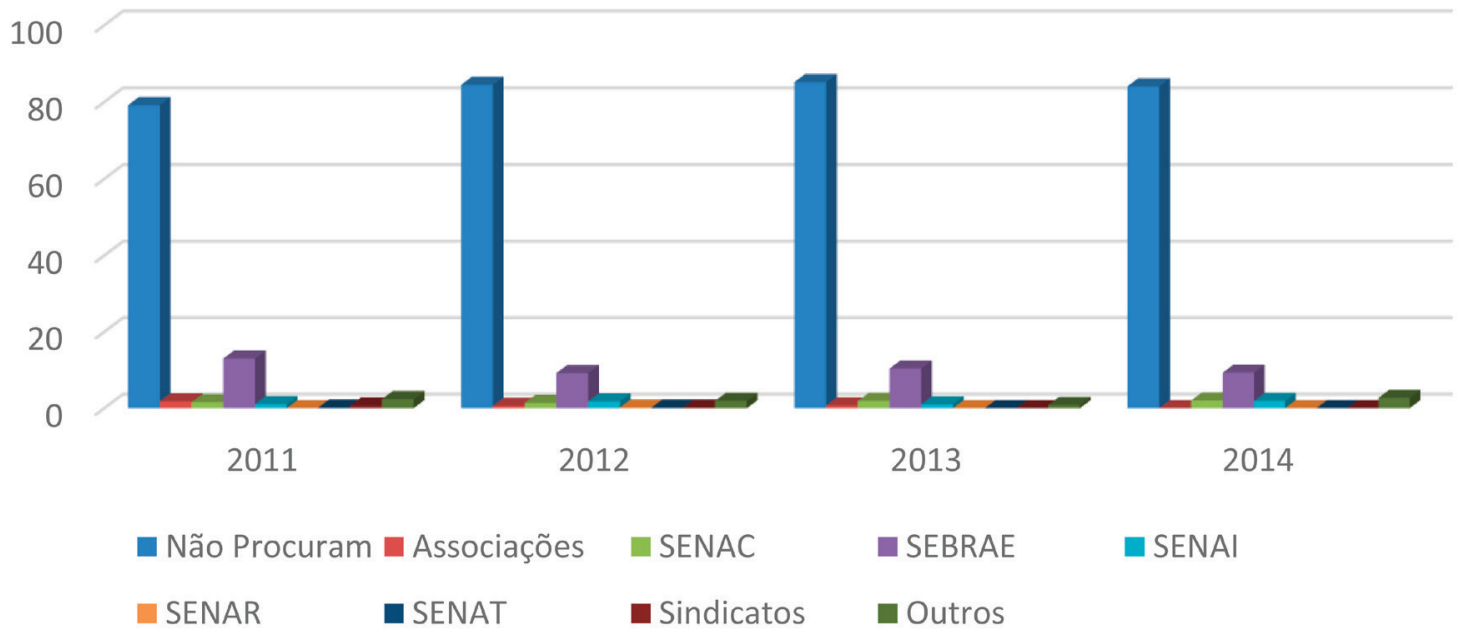

Gráfico 7 - Órgãos procurados por empreendedores e empreendedores que não procuram apoio Fonte: elaborado pelo autor de acordo com dados contidos nos $\operatorname{GEM}(2012,2013,2014,2015)$.

Por meio das análises de toda essa evolução, pode-se conceituar melhor sobre o assunto e chegar aos motivos dessas evoluções e possíveis impactos que elas podem causar no sucesso e na longevidade das organizações.

\subsection{RESULTADOS E DISCUSSÕES}

A falta do planejamento prévio faz que as empresas abram sem analisar aspectos básicos. De acordo com estudos do SEBRAE, $46 \%$ dos empreendedores não sabiam, antes de abrir o próprio negócio, o número de clientes no de negócio para viabilizar o empreendimento ou uma nova segmentação de mercado.

Então, pode-se associar ao alto nível de mortalidade das empresas a falta de planejamento e da confecção do plano de negócio. Caso todos os empreendedores procurassem um órgão de apoio e se propusessem a executar o planejamento, o índice de mortalidade das empresas seria reduzido drasticamente.

O plano de negócio se torna importante para a empresa e pode aumentar as suas chances de sucesso e de longevidade, como citado por Dornelas (2014). São importantes a confecção 
e a execução de um plano de negócio nas primeiras diretrizes dos novos empreendimentos.

\section{CONSIDERAÇÕES FINAIS}

Este artigo teve como objetivo mostrar a importância do plano de negócio para os empreendedores e como o uso dele pode mudar o cenário econômico do país. Para a realização da análise, observou-se a porcentagem de empreendedores que procuraram algum tipo de instrução para iniciar seu negócio e quais impactos essa orientação, por meio dos órgãos de apoio, podem causar na sua organização. Foram utilizados os relatórios executivos dos anos de 2013 a 2015 e o relatório completo do ano de 2012 , ambos disponibilizados pelo Serviço Brasileiro de Apoio às Micro e Pequenas Empresas (SEBRAE). No trabalho, foram analisados o perfil dos empreendedores e a evolução deles, para que, com isso, pudesse chegar a uma melhor posição da importância do plano de negócio para a sobrevivência da empresa.

O plano de negócio se torna importante para qualquer organização devido à utilização como ferramenta estratégica de vantagem competitiva. Durante o trabalho, pôde-se perceber a quantidade de pessoas que não tinham informações básicas sobre o seu próprio negócio e a grande quantidade de empresas que tiveram de fechar suas portas devido à falta de planejamento, seja ele estratégico, financeiro, marketing ou operacional.

A importância do plano de negócios se torna visível ao passo que os empreendedores conseguem utilizá-lo como ferramenta para se destacar no ramo de inovação e novos mercados, uma vez que, combinado com as suas características, o plano pode ser o fator crucial da vantagem competitiva por aproximar o desejo e a realidade de um segmento específico.

Ao desenvolver as análises para este estudo, surgiram algumas limitações para o estudo com relação às informações sobre os empreendedores que procuram algum tipo de órgão. A partir de 2012, esses dados foram disponibilizados pelo SEBRAE, porém não atinge o período total do trabalho. Uma melhor análise pode ser feita em breve com os novos relatórios confeccionados pelos órgãos de apoio, atingidos pelas ferramentas descritas na metodologia.

Como sugestões para pesquisas futuras, pode-se analisar o perfil dos empreendedores e evidenciar como isso impacta na economia local. E como conselho para novos empreendedores e curiosos da área, a dica que fica é a importância desse planejamento, pois, se alguém deseja o sucesso da sua empresa, o primeiro passo é planejar.

\section{THE IMPORTANCE OF THE BUSINESS PLAN FOR THE SUCCESS AND LONGEVITY OF ORGANIZATIONS}

\section{ABSTRACT}

This study enabled an analysis of entrepreneurship index in the last ten years, through data provided by companies and public agencies such as SEBRAE, IBGE, among others. The study was aimed at analyzing the importance of the business plan for the longevity of organizations. The data analyzed relates the types of retail, gender and age of entrepreneurs and the proportion of entrepreneurs seeking some kind of knowledge and support to start their enterprise. The research carried out was bibliographical and documental, based on reports that were published within the last ten years by the aforementioned organs. We sought and found information that made it possible to better understand the types of entrepreneur and how they behave in the economy. We concluded that entrepreneurs who seek help, knowledge, and execute a business plan tend to be successful; also, we determined that there has been an increase in the number of female entrepreneurs.

Keywords: Entrepreneurship. Business plan. SEBRAE. 


\section{LA IMPORTANCIA DEL PLAN DE NEGOCIOS PARA EL SUCESO \\ Y LA LONGEVIDAD DE LAS ORGANIZACIONES}

\section{RESUMEN}

Este artículo viabilizó el estudio de los índices de emprendimiento en los últimos diez años, por medio da datos puestos a disposición por SEBRAE, IBGE y otros. El estudio tuvo como objetivo analizar la importancia del plan de negocios para la longevidad de las organizaciones. Se analizaron los datos que relacionan los tipos de ventas, de género, de edad de los emprendedores y la proporción de emprendedores que buscan algún tipo de conocimiento y apoyo para iniciar su emprendimiento. La investigación se caracteriza como un estudio bibliográfico y documental, utilizando informes de los últimos diez años de los mencionados órganos. Se alcanzaron informaciones que posibilitaran mejor entender los tipos de emprendedores y cómo ellos se comportan en la economía. Se concluyó que los emprendedores que buscan conocimiento y que ejecutan el plan de negocios tienden a tener suceso en el mercado y que hay un aumento en el número de mujeres emprendedoras.

Palabras-clave: Emprendimiento. Plan de Negocios. SEBRAE.

\section{L'IMPORTANCE DU PLAN DES AFFAIRES POUR LE SUCCES ET LA LONGEVITE DES ENTREPRISES}

\section{RESUME}

Cet article a rendu posible une études des taux d'entrepreunariat dans les dix dernières années, à travers des données mises à disposition par SEBRAE, IBGE, entre autres. L'étude a eu comme objectif l'analyse de l'importance du plan des affaires pour la longévité des organisation. Nous avons analysé des données qui mettent en relation les différents types de ventes, genre et âge des entrepreneurs, ainsi que la proportion des entrepreneurs qui cherchent des connaissances et du soutien avant d'initier leurs entreprises. La recherche est bibliographique et documentaire, basée sur des rapports des dix dernières années des organes susmentionnés. Les informations atteintes ont permis de mieux comprendre les types d'entrepreneurs et comment ils se comportent dans l'économie. Nous avons conclu que les entrepreneurs qui cherchent des connaissances et qui exécutent un plan d'affaires ont tendance à avoir du succès dans le marché, ainsi que il y a une augmentation dans le nombre d'entrepreuneuse.

Mots-clés: Entrepreunariat. Plan d'affaires. SEBRAE.

\section{REFERÊNCIAS}

BARON, R. A.; SHANE, S. A. Empreendedorismo: uma visão do processo. São Paulo: Cengage Learning, 2013.

BÔAS, B. V. Metade das empresas fecha as portas no Brasil após quatro anos, diz IBGE. 2015. Disponível em: <http://www1.folha.uol. com.br/mercado/2015/09/1677729-metade-das-empresas-fecha-as-portas-no-brasil-apos-quatro-anos-diz-ibge.shtml>. Acesso em: 5 out. 2016.

CERVO, A. L.; BERVIAN, P. A.; SILVA, R. Metodologia científica. 6. ed. São Paulo: Pearson Prentice Hall, 2007.

DOLABELA, F. O segredo de Luísa. 30. ed. São Paulo: Editora de Cultura, 2006.

DORNELAS, J. Empreendedorismo: transformando ideias em negócios. 5. ed. Rio de Janeiro: LTC, 2014.

FONSECA, J. C. No Brasil, quase metade das empresas abertas fecha em três anos, diz IBGE. 2011. Disponível em: <http://re- 
vistagestaoenegocios.uol.com.br/gestaomotivacao/48/artigo273388-1.asp/>. Acesso em: 5 out. 2016.

GEM - GLOBAL ENTREPRENEURSHIP MONITOR. Relatório. Curitiba, 2012. Disponível em: $<$ http://www.bibliotecas.sebrae.com. br/chronus/ARQUIVOS_CHRONUS/bds/bds. nsf/c6de907f e0574c8ccb36328e24b2412e/\$File/5904.pdf $\geq$. Acesso em: 20 set. 2016.

Relatório Executivo. Curitiba, 2013. Disponível em: <http://www.bibliotecas. sebrae.com.br/chronus/ARQUIVOS CHR ONUS/bds/bds.nsf/c6de907fe0574c8ccb36328e24b2412e/\$File/5904.pdf $\geq$. Acesso em: 20 set. 2016.

. Relatório Executivo. Curitiba, 2014. Disponível em: $<\mathrm{http} / / / \mathrm{www}$.bibliotecas. sebrae.com. br/chronus/ARQUIVOS_CHR ONUS/bds/bds. nsf/c6de907fe0574c8ccb36328e24b2412e/\$File/5904.pdf $\geq$. Acesso em: 20 set. 2016.

. Empreendedorismo no Brasil 2015: relatório executivo. Curitiba, 2015. Disponível em: <http://www.bibliotecas. sebrae.com. br/chronus/ARQUIVOS_CHRONUS/bds/bds. nsf/c6de907fe0574c8ccb36328e24b2412e/\$File/5904.pdf $\geq$. Acesso em: 20 set. 2016.

GIL, A. C. Métodos e técnicas de pesquisa social. 6. ed. São Paulo: Atlas, 2008.

HISIRICH, R. D.; PETERS, M. P.; SHEPHERD, D. A. Empreendedorismo. 7. ed. Porto Alegre: Bookman, 2009.

MAMEDE, M. I. de B.; MOREIRA, M. Z. Perfil de competências empreendedoras dos investidores Portugueses e Brasileiros: um estudo comparativo na rede hoteleira do Ceará. In: ENANPAD, 2005, Brasília. Anais... Brasília: Anpad, 2005.

OLIVEIRA NETTO, A. A. Metodologia da pesquisa científica: guia prático para apresen- tação de trabalhos acadêmicos. 2. ed. Florianópolis: Visual Books, 2006.

SCHOLZ, R. H.; CAUSSI, L. S. Mercado de food truck sob uma perspectiva de inovação e empreendedorismo. Revista Brasileira de Gestão e Inovação, Caxias do Sul, v. 4, n. 3, p. 1-23, 2017. 